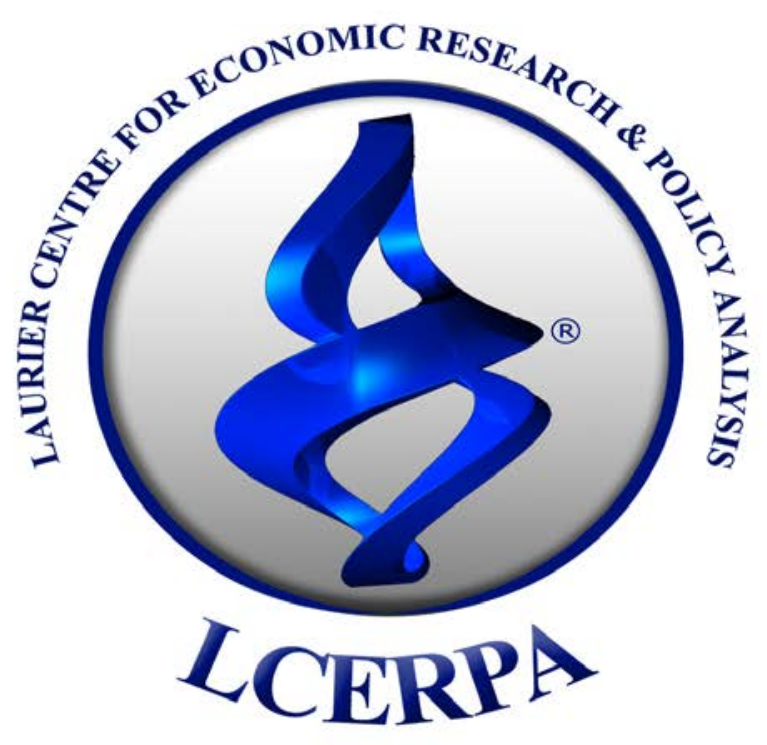

Economic Research Paper: 2014-5

\title{
WHEN IS LIFT-OFF? \\ EVALUATING FORWARD GUIDANCE FROM THE SHADOW
}

Matthias Neuenkirch * and Pierre L. Siklos **

MARCH 2014

* University of Trier

$* *$ Wilfrid Laurier University 


\title{
WHEN IS LIFT-OFF?
}

\section{EVALUATING FORWARD GUIDANCE FROM THE SHADOW*}

\author{
Matthias Neuenkirch \\ Department of Economics \\ University of Trier \\ Trier, GERMANY \\ and \\ Pierre L. Siklos \\ Department of Economics, Wilfrid Laurier University \\ Balsillie School of International Affairs \\ Waterloo, ON, CANADA
}

* Research for this paper was carried out in part while the first author visited the Viessmann Centre. Siklos also gratefully acknowledges financial assistance from a CIGI-INET research grant. The first author has been a member of the C.D. Howe's Monetary Policy Council (MPC) since 2008 (the MPC exists since 2002) but receives no direction or funding from the C.D. Howe for participating in this group. All members of the MPC, including the second author, provide an independent opinion on monetary policy issues.

Pierre Siklos: psiklos@wlu.ca, Matthias Neuenkirch: neuenkirch@uni-trier.de. 


\begin{abstract}
Monetary policy decisions are typically taken after a committee has deliberated and voted on a proposal. However, there are well-known risks associated with committee-based decisions. In this paper we examine the record of the shadow Monetary Policy Council in Canada. Given the structure of the committee, how decision-making takes place, as well as the voting arrangements, the MPC does not face the same information cascades and group polarization risks faced by actual decision-makers in central bank monetary policy councils. We find a considerable diversity of opinion about the recommended future path of interest rates inside the MPC. Beginning with the explicit forward guidance provided by the Bank of Canada market determined forward rates diverge considerably from the recommendations implied by the MPC. There is little evidence that the Bank and the MPC coordinate their future views about the interest rate path. However, it is difficult to explain the basis on which median voter inside the MPC, as well as doves and hawks on the committee, change their views about future changes in policy rates. This implies that there remain challenges in understanding the evolution of future interest rate paths over time.
\end{abstract}

Keywords: Bank of Canada, central bank communication, committee behaviour, monetary policy committees, shadow councils, Taylor rules.

JEL Classifications: E43, E52, E58, E61, E69 


\section{Introduction}

Monetary policy is typically delivered after a committee has deliberated economic conditions and a proposal to change, or not, the policy rate has been taken by a vote. There exist, of course, a diversity of approaches to how votes are taken. In the wake of the global financial crisis, and the lowering of policy rates in the industrial world to levels close to or at the zero lower bound, attention has turned to other strategies used by central banks to influence expectations. In this environment, some monetary authorities have turned to forward guidance to influence inflation expectations and, by implication, interest rates across the (whole) term structure.

Although forward guidance has existed in a variety of forms since the late 1990s, a more explicit and time-contingent form of forward guidance was pioneered by the Bank of Canada in April 2009 when, faced with a policy rate effectively at the zero lower bound, a conditional commitment was made to maintain extraordinarily low rates for up to a calendar year. Unfortunately, other than publishing some macroeconomic forecasts, the Bank of Canada does not release a forward interest rate path. Several other central banks, including most recently the U.S. Federal Reserve, have become more transparent in this connection. Moreover, given how the Bank is governed, no minutes or votes of its policy-making Governing Council are published. This limits researchers' ability to examine the record of forward guidance and policy stance setting of the Bank of Canada.

However, the decisions of the Bank of Canada are 'shadowed' by the Monetary Policy Council (MPC), a body administered by a non-partisan think tank, the C.D. Howe Institute 
(CDHI). This committee recommends a policy rate setting for the Bank of Canada as well as providing a forward interest rate path, up to a year ahead. Moreover, the independent (and unpaid) members of the MPC provide individual recommendations about the future path of the Bank of Canada's policy rate. These are publicly available and are empirically studied in this paper.

We are interested in how much diversity of opinion exists about the appropriate future stance of monetary policy and the extent to which observable institutional and economic factors can explain individual recommendations over time. We also compare the MPCs recommendations against observed future decisions made by the Bank of Canada as well as financial market views about the future of short-term interest rates. Briefly, we find that there exists considerable disagreement within the MPC over time about the recommended future interest rate path. We also report significant differences of opinion between the MPC and financial markets about the future direction of interest rates. Moreover, while the Bank of Canada, financial markets, and the MPC recommendations and views about future interest rates generally parallel each other, there appears to be little evidence that these views are somehow coordinated. Nevertheless, while few economic indicators explain how MPC members change their future interest rate paths, differences are found to be sensitive according to whether interest rates are rising or falling and the period of explicit forward guidance also seems to have an impact on the immediate policy rate recommendation. MPC members, in particular, appear to have taken seriously the conditional nature of the Bank of Canada commitment on future policy rates. 
The rest of the paper is organized as follows. In Section 2, we briefly explain how the Bank of Canada and the shadow MPC make monetary policy decisions. In Section 3, we survey recent work and evidence in relation to the principle of forward guidance around the world. In Section 4, we consider some stylized facts as well as some empirical evidence on the behavior and determinants of future interest rate paths set by the MPC in relation to subsequent decisions taken by the Bank of Canada as well as market determined future interest rates. The paper concludes with a summary and future research that remains to be done.

\section{The Shadow Council and Observed Monetary Policy}

Ever since Canada adopted inflation targeting in the early 1990s, together with the adoption of a fixed schedule for the announcement of the policy rate since $2000^{1}$, it has become easier to follow monetary policy and assess its stance. In part as a reaction to these developments a nonpartisan public policy think tank, the C.D. Howe Institute (CDHI, www.cdhowe.org), created a shadow monetary policy committee called the Monetary Policy Council (MPC). The mandate of this shadow committee is not to second guess the policy strategy of the Bank of Canada (BoC), nor does it attempt to forecast future Bank of Canada policy, but its aim is to provide a second opinion, that is, a recommendation about the appropriate stance of future monetary policy.

The government and the central bank operate under a mandate to target inflation in consumer prices in a $1-3 \%$ range with the express aim to maintain inflation in the headline Consumer Price Index (CPI) at 2\%, the mid-point of the target range. The agreement with the

\footnotetext{
${ }^{1}$ The policy rate is the interest rate target on overnight borrowing by major financial institutions. An operating band is permitted around the target which the Bank can control. See http://www.bankofcanada.ca/monetarypolicy-introduction/key-interest-rate/.
} 
government is renewed every five years and, since 1998, the inflation objective has remained unchanged. In contrast, the MPC is tasked with providing a recommendation on what the appropriate setting for the policy rate ought to be conditional on the objective of achieving the $2 \%$ inflation target. $^{2}$

Whereas the Bank of Canada typically makes a policy rate announcement on Wednesdays, the MPC meets the previous Thursday. ${ }^{3}$ There are at least three important substantive differences between the operation of the MPC and its counterpart at the Bank of Canada, called the Governing Council (GC). First, and most relevant for the purposes of the present study, the shadow committee not only recommends a policy rate for the upcoming BoC setting but provides recommendations for the following meeting as well as meetings 6 and 12 months ahead. The last two types of recommendations were introduced in 2007 and 2010, respectively. In contrast, the BoC provides no forward interest rate path. Second, the BoC does provide macroeconomic forecasts though this is a fairly recent innovation. MPC members do not publish forecasts. ${ }^{4}$ Indeed, it is only recently (2010) that the BoC has published a two year ahead fan-type chart for inflation. Previously, and then again only since 2005, has the Bank provided an own forecast for inflation and real GDP growth. Third, while individual committee member recommendations are published, alongside a consensus press release explaining the

2 Complete details about the Bank's monetary policy strategy can be found at http://www.bankofcanada.ca/monetary-policy-introduction/framework/inflation-control-target/.

3 Prior to 2013, the Bank of Canada's policy rate announcement was made on Tuesdays. Since then the Bank has been able to release its quarterly Monetary Policy Report (a further four interim updates of which are also published) earlier permitting the simultaneous release. The MPC discussed the possibility of delaying its own policy rate announcement but chose to retain the Thursday meeting schedule.

${ }^{4}$ Note that the organizations the professional economists on the MPC represent do publish forecasts which are routinely discussed inside the MPC. 
median recommendation and the tone of the committee deliberations, the BoC issues only a press release. The GC is not a body recognized in the Bank of Canada Act. It is a creation of a former BoC Governor, Gordon Thiessen, during the 1990 s. ${ }^{5}$ As a result, the central bank does not publish votes or minutes of its policy making body.

The MPC consists of 12 individuals, half of whom are academics while the remaining members are professional economists broadly representing the financial sector. The GC consists of six members, and includes the Governor, the Senior Deputy-Governor, and four Deputy-Governors. ${ }^{6}$ Details about the governance structure and decision-making by the GC as well as details about how the MPC conducts its meetings and the preparation of the press release can also be found in Siklos and Neuenkirch (2013). Members vote individually on recommendations for the upcoming Bank of Canada overnight rate setting, the one after that, as well as recommendations 6 and 12 months ahead. ${ }^{7}$ There are no pre-meetings or other organized consultations between MPC members prior to any decisions. The setup of the MPC encourages individual voting.

\section{Varieties of Forward Guidance}

Forward guidance as a principle for providing fewer surprises about the likely future stance of monetary policy is a development of the early 1990s, possibly pioneered by the U.S. Federal

\footnotetext{
${ }^{5}$ It is conceivable that the Governing Council was created by former Governor Gordon Thiessen in reaction to the so-called Manley Report (see Manley and Dorin 1992) which essentially concluded that, when it comes to Bank of Canada governance, "if it ain't broke, don't fix it". Also, see Laidler (1991).

${ }^{6}$ The current and past membership of the MPC can be found at http://www.cdhowe.org/monetary-policy-council$\underline{2}$ while the Bank's current GC membership is available at http://www.bankofcanada.ca/about/corporategovernance/governing-council/.

7 12-month ahead recommendations began to be published in January 2010. The resulting small sample (28 observations) makes it unattractive to utilize these data.
} 
Reserve when it sought to provide additional information in the directive the Federal Open Market Committee (FOMC) publishes about the likely future stance of monetary policy. The Bank of Japan also introduced a form of forward guidance in 1999 when it committed to keep its policy rate at the zero lower bound (ZLB) until deflation expectations dissipated. Historically, however, the Fed's usage of forward guidance has been applied in fits and starts. Until the late 1990 s it was in the form of asymmetric guidance, that is, whether the future might bring tightening or loosening of monetary policy (e.g., see Thornton and Wheelock 2000). Thereafter the Fed introduced the concept of the 'balance of risks'. When deflation became a cause of concern for U.S. policy makers in the early 2000s, the notion of keeping policy rates at a certain level for an 'extended period of time' entered the lexicon of central banking. In any event these episodes only later came to be called narrative or 'open-ended' forms of forward guidance.

The concept of forward guidance, as it is now understood, is practiced differently across central banks that have deployed this strategy in recent years. Nevertheless, all forms of forward guidance have in common the notion that the central bank provides some information about the future path of interest rates (e.g., Coeuré 2013). Some central banks (e.g., Norway's Norges Bank, Sweden's Riksbank, the Czech National Bank, and the Fed) provide numerical estimates of expected future policy rates while others (e.g., Canada, the ECB) are less explicit. ${ }^{8}$ Reliance on this kind of strategy for communicating the stance of monetary policy has taken on a greater urgency since the GFC when the room to manoeuvre on the policy rate effectively

\footnotetext{
${ }^{8}$ Another distinction is whether the path is purely model-driven or represents the views of the policy making committee members. Several authors (e.g., Kool and Thornton (2012), Karagedikli and Siklos (2013), and references therein) examine the impact of forward interest rate paths on yields and the exchange rate. The evidence of their impact on expectations is decidedly mixed.
} 
vanished as several central banks approached or reached the ZLB. The Fed has since been at the forefront in experimenting with different types of forward guidance (e.g., see Williams 2013).

Since that time forward guidance has come to be viewed as another policy tool which, under certain circumstances, can be used to stimulate the economy, reduce policy making uncertainty, uncertainty about the inflation-output trade-off, and provide breathing room for the transmission mechanism of monetary policy to return to normal. ${ }^{9}$ It is in large part for this reason that forward guidance as an instrument evolved into time-contingent and, more recently, state-contingent, forms (e.g., Carney 2013). Indeed, the Bank of Canada can be said to have pioneered the time-contingent version of the strategy when it announced, in April 2009, its commitment to keep the policy rate at the effective zero lower bound for up to a year. The conditions were seen, ex post, to have been met when the BoC invoked the need to raise the policy rate in April 2010, one meeting prior to the expiry of the promise to hold the rate at the ZLB. He (2010) found that the policy did move yields in the desired direction, as did Siklos and Spence (2010), while Siklos and Neuenkirch (2013) examined the effect of the Bank of Canada's conditional commitment on the CDHI's MPC current policy rate recommendation. They conclude that the MPC's current recommended overnight rate was lower relative to the value arrived at in a counterfactual experiment where no conditional commitment was made.

More recently, as advanced economies struggle to return to more 'normal' economic growth, forward guidance has become state-contingent in at least two cases. First, in 2012, and

\footnotetext{
${ }^{9}$ By the time the Great Moderation ended around 2007, central bankers became fond of relying on the Taylor rule as a device to communicate the stance of monetary policy while stressing the fact that actual monetary policy must adhere to the rule in a flexible manner. For example, see Poole (2006).
} 
more recently in 2013, the Fed and the Bank of England have committed to the ZLB so long as the unemployment rate remains above a certain threshold (6.5\% for the U.S., $7 \%$ for the U.K.). Both central banks have been explicit about the importance of not interpreting the thresholds as triggers for tighter policy (e.g., see Bank of England 2013). Conditionality also remains at the forefront as these same central banks underscore the need to remain faithful to their remit, a medium-term inflation target for the Fed and a $2 \%$ inflation target for the Bank of England. ${ }^{10}$ Interestingly, as pointed out by Weale (2013), a member of the Bank of England's MPC, forward guidance has "raised the bar" about whether a tightening of the stance of monetary policy is in order when expectations of inflation begin to rise. This view is also consistent with the theoretical position outlined by Woodford (2012) who proposed that keeping policy rates low for longer than would be expected, under a rule that policy ought to be tightened when expectations of inflation rise, provides the economic stimulation necessary to achieve 'escape velocity' from sluggish economic growth (also see Carney 2013a). Of course, as even those who are skeptical about the impact of forward guidance will stress, central bank credibility is essential for the strategy to be successful.

It is well known that since monetary policy decisions are made by committees a variety of risks arise thereof (e.g., see Sibert 2006, Maier 2010). There is the free rider problem when a committee member simply agrees with others who voted ahead of them. A variant of this problem is the possibility of information cascades. Here the focus is on committee members who might choose to ignore independent signals in arriving at their voting decisions.

\footnotetext{
${ }^{10}$ The Fed has the advantage in this context of being able to rely on its dual mandate to maintain price stability while striving to support an economy that operates at capacity.
} 
Committees are also prone to being cautious, or perhaps conservative, in an attempt to paper over differences or to emphasize the desirability of achieving decisions by consensus. Finally, committees may become polarized leading to more extreme decisions than might otherwise be the case. This phenomenon may be revealed either by excessive caution or by excessive risktaking.

As noted above, the Bank of Canada does not publish a forward interest rate path nor does it publish minutes of the meetings of the policy making committee or the votes of its members. In contrast, the CDHI's MPC does publish a forward rate path and the individual votes of its committee members. To illustrate consider Figure 1 which shows the forward rates for the median, most dovish and most hawkish members of the MPC at eight different meetings over the period 2007 through mid-2013. ${ }^{11}$ Perhaps the most striking result from a visual inspection of the figure is that, with very few exceptions, MPC members of all stripes advocated 'lift-off' for the policy rate throughout the sample, even during the implementation of forward guidance between April 2009 and April 2010. The median voter recommends a lower policy rate during the height of the GFC (December 2008) while the dove and hawk recommend an unchanged policy rate over the one year horizon MPC members are asked to take a stand on. Otherwise the main difference between median, dove, and hawkish recommendations is not the sign of the suggested future change in the policy rate but, rather, the speed with which future rates should rise. Clearly, the recommended future rise is faster among hawks than for doves.

\footnotetext{
${ }^{11}$ The dove is defined as the MPC member who consistently recommends the lowest policy rate for the Bank of Canada for the upcoming overnight rate setting by the Bank. Obviously, the most hawkish member recommends the highest overnight rate. There can be more than one dove or hawk at the conclusion of an MPC meeting. Also, the individual labelled as dove or hawk can, and does of course, change over time.
} 
Nevertheless, as we shall in the following section, there remain substantial differences of opinion between the members of the MPC about the appropriate policy rate.

Notice also that, for each of the meetings shown in Figure 1, all members must reset their most immediate policy rate proposal to the rate actually set by the Bank of Canada at its previous meeting. Clearly, over the roughly seven years of rate setting shown, all members of the MPC have effectively been more hawkish about the Bank of Canada turned out to be, at least ex post. Since we do not observe GC members' views about when 'lift-off' of the policy rate might take place, unlike their counterparts at the FOMC, we cannot say whether the MPC has been more hawkish about the future than their counterparts at the Bank of Canada.

Moreover, given the organizational structure of the CDHI's MPC, some of the problems associated with conventional policy committees do not apply. Members do not know, a priori, who will vote first nor does the Chair make a recommendation that may be rejected in favor of an alternative. Since the committee members individually provide a recommendation to the Bank of Canada there is no commitment to maintain the recommendation in future since the MPC must take as given the stance that the Bank actually took once a decision has been published. Hence, the behavior of the MPC can be viewed as a laboratory of sorts for how monetary policy committees behave in the absence, at least most of the time, of an interest rate path provided by the Bank of Canada even when some kind of forward guidance is provided. Finally, unlike markets and the public, which may be inattentive to the nuances that accompany central bank policy rate decisions, the CDHI's MPC is well aware not only of the 
decision take by the Bank of Canada but also the words that accompany these announcements and the reasoning behind them.

\section{The Record of Forward Guidance: Data, Stylized Facts, and Empirical Evidence}

\subsection{Data and Stylized Facts}

The BoC's GC naturally must worry about the credibility of its policies. It is obvious that some of this credibility does spillover into the deliberations and recommendations of the CDHI's MPC. However, while the BoC publishes macroeconomic forecasts it does not publish a forward interest rate path. Similarly, the wisdom of the MPC's forward interest rate recommendations can be examined ex post to determine whether the shadow committee reacted to expected inflation and economic growth in Canada.

The empirical evidence below relies on monthly data since March 2007, when the CDHI's MPC introduced a proposal on the interest rate in 6-months' time. As previously mentioned the MPC makes several recommendations at each meeting. It recommends a policy rate for the Bank of Canada's next meeting (4 or 5 days later), a policy rate recommendation for the meeting after that (approximately 6 weeks after that) and a recommendation for the policy rate in 6 months' time. ${ }^{12}$ Figures 2 and 3 show a variety of policy rate and policy rate expectations or recommendations. Figure 2 demonstrates that substantial differences of opinion about the 6 months ahead policy rate recommendation persist within the MPC. The gap often ranges between 100 to 150 basis points between the hawks and doves on the committee. Notice also

\footnotetext{
12 In 2010, the MPC began to publish a one-year ahead interest rate recommendation. Unfortunately, there is an insufficient number of observations to include these in the present analysis.
} 
that the highest and lowest policy recommendations appear more volatile than the median policy rate recommendation.

Figure 3 compares the CDHI's MPC 6 months ahead median policy rate recommendation against the Bank of Canada's actual stance as well as a market indicator of future interest rates, namely the 3 month forward BA rate. ${ }^{13}$ The latter represents the yield on bankers' acceptances, a highly liquid and widely used indicator of short-term interest rates in Canada. ${ }^{14}$ Once again it is evident from the three lines that there exists a diversity of opinions about future policy rates not only between the Bank and financial markets but also between both of these indicators and the Bank of Canada's actual policy rate setting. Interestingly, while the correlation between the forward BA yield and the MPC recommendation is high until early 2009 the two indicators diverge persistently thereafter. Indeed, between 2010 and 2012, the MPC's recommendation for the Bank of Canada's policy rate 6 months ahead is consistently above the actual policy rate. Essentially, the reverse is true of the 3 months ahead BA over approximately the same period. Of course, the Bank of Canada adopted a particular form of forward guidance from April 2009 to April 2010, as discussed previously.

Figure 4 provides a slightly different perspective on the discrepancies between the Bank of Canada's views and those of the CDHI's MPC median voter. With two minor exceptions, the MPC revised its forward interest rate proposal by more than the observed change in the Bank of Canada's actual policy rate during the 6 months period. Interestingly, the MPC

\footnotetext{
${ }^{13}$ Unfortunately, we are unable to obtain a long enough sample for a 6 months ahead BA yield.

${ }^{14}$ Bankers' acceptances are short-term obligations that are accepted by banks such that there is a guarantee of repayment of principal and interest. For additional details, see http://www.m-x.ca/f publications en/BA en.pdf.
} 
recommendations fall considerably faster than the Bank's actual future policy rate beyond the conditional commitment policy is introduced in April 2009. From the spring of 2012 onwards, neither the MPC revised its proposal nor the GC did change the target rate.

Hence, it is of considerable interest to ask: can we explain these persistent differences based on how the committee deliberates and makes decisions? Alternatively, to what extent are observable macroeconomic or financial factors responsible for these differences of views? A series of regressions below consider these questions. Since, as noted from Figure 2, committee members have substantially differing views about the appropriate policy rate in future, we also ask whether observable determinants, both of the institutional and macroeconomic or financial varieties, can explain within committee differences in views about the appropriate stance of monetary policy going forward.

As discussed above there are relatively fewer pressures on the MPC to fall victim to information cascades or group polarization, a problem that can emerge in several committee settings. As a result, if information is processed or interpreted differently, there is scope for considerably greater disagreement about the future course monetary policy in Canada ought to follow. This is illustrated in Figure 5 which plots the standard deviation of individual MPC committee member recommendations for future policy rate. It is clearly seen that the correlation between the recommendations for the upcoming and meeting after that is very high. In contrast, recommendations for the policy rate in 6 months time reveal a much higher standard deviation which is also more variable than the other two recommendations. Indeed, if the standard deviation proxies the level of disagreement within the committee then there is 
comparatively much less disagreement about the near term stance that monetary policy should take while disagreement is much higher much of the time at the 6 months horizon. While this is not entirely surprising it is interesting that disagreement about the course that the Bank of Canada should take over a four day to 6 months horizon is similar in early 2009 as well as in early 2013. The period in early 2009 anticipates, of course, the time-contingent commitment pioneered by the Bank of Canada in April 2009. In early 2013 there was similarly growing consensus globally that central bank policy rates would not be rising for the foreseeable future.

\subsection{Econometric Evidence}

We now turn to some econometric evidence. We estimate the following three specifications to provide evidence about the questions posed in the paper.

$$
\begin{gathered}
i_{t+6}^{k}=\alpha_{0}+\alpha_{1} i_{t+6}^{j}+\varepsilon_{t} \\
\Delta i_{t+6}^{M P C}=\beta_{0}+\boldsymbol{\beta}_{1} \mathbf{Z}_{t}^{f}+v_{t} \\
D I S_{t+m}^{M P C}=\lambda_{0}+\lambda_{1} \Phi_{t}+\lambda_{2} \Omega_{t-1}+\xi_{t}
\end{gathered}
$$

Equation (1) explores the predictive power of the CDHI's version of forward guidance for the Bank of Canada policy rate setting 6 months ahead. Alternatively, we also ask whether financial markets views about the future course of short-term interest rates (i.e., the 3 months forward BA yield) successfully forecast the BoC's rate in 6 months. Hence, for the estimations in presented later in Tables $1 a$ and $1 b k$ refers to the $\mathrm{BoC}$ and $j$ to the MPC or BA. A second set of estimations (shown in Tables 2a-2c) aims at predicting the the MPC's 6 months ahead recommendations as left-hand side variable $k$ with the 3 month BA returns $j$. 
Equation (2) considers the determinants of changes in the MPC's views about the BoC's policy rate 6 months ahead. The specification examines the extent to which the shadow committee's view about future interest rates is explained by forward looking variables. It is standard practice to argue that monetary policy ought to be forward-looking, especially when the central bank is required to meet an inflation target. Motivated by the Taylor rule two obvious proxies for how forward looking the MPC is are changes in Canadian inflation and real GDP growth forecasts. Given the openness of the Canadian economy and the worldwide tendency to keep interest rates close to or at the ZLB, we also include changes in the corresponding US and euro area (EA) forecasts. Finally, changes in the VIX-20 index are included to proxy volatility on financial markets.

Equation (3) asks about the sources of disagreement (DIS) within the MPC over the future path for the Bank of Canada's policy rate. If we define disagreement as the standard deviation of individual proposals for future monetary policy settings then we can ask to what extent these disagreements are driven by institutional, financial or macroeconomic factors. These factors include the fraction of voting members who are professional as opposed to academic economists, the share of voting members who were physically present at the MPC meeting, as opposed to participating via conference call, the period of the conditional commitment (i.e., April 2009-April 2010), lagged disagreement of the MPC voting members with the subsequently observed Bank of Canada overnight rate setting, the VIX, and the conditional standard deviation of observed inflation. Additionally, we wish to consider the possibility that disagreement about future interest rate paths may differ as between periods when interest rates are rising versus falling rates. 
Regression results are shown in Tables 1 to 4 . OLS is used throughout. Tables $1 \mathrm{a}$ and $1 \mathrm{~b}$ provide estimates of equation (1). Tables $1 \mathrm{a}$ and $1 \mathrm{~b}$ presents two sets of results also allowing for the possibility that future interest rate paths behaved differently during the pre-conditional commitment period. ${ }^{15}$ It is immediately clear that there is a less than one to one relationship between changes in both the shadow committee's and financial markets' views about the future path of policy rates and the actual overnight rate 6 months ahead. Nevertheless, the CDHI's MPC views come closest to ones eventually taken by the Bank of Canada based on the explanatory power of the different regressions. In contrast, changes in the forward BA can only explain approximately two-thirds of the eventual Bank of Canada policy rate. Finally, we observe only small differences according to whether the median, hawks or doves on the MPC are considered.

Turning to the interest rate path prior to April 2009, Table $1 \mathrm{~b}$ essentially reveals that, prior to the period of the conditional commitment, a 100 basis point change in either the MPC minimum recommendation for future overnight rates or the forward BA rate results in a 100 basis point change in the Bank of Canada's policy rate 6 months into the future. Whether this is reflects the 'follow the market' principle discussed in Blinder (2004) wherein central banks deliver the monetary policy that 'markets' or, in this case, 'experts' also recommend, is unclear. Nevertheless, tests shown in both part of the Table suggest that both the MPC and the forward BA are not unbiased estimates of future Bank of Canada policy rates. Clearly then, there is more

\footnotetext{
${ }^{15}$ Note that forecasting the Bank of Canada in the post-conditional commitment period is not feasible: there is no variation in the policy rate.
} 
to Bank of Canada policy rate moves than simply following markets. ${ }^{16}$ The sole exception is the interest rate paths recommended by MPC doves when considering the full sample period. Of course, the table does not indicate the source of the bias. Subsequent results discussed below may help in providing possible explanations for this finding.

Tables $2 a$ through $2 c$ provide further estimates of Equation (1). These results are meant to investigate differences between the MPC and financial markets views about future interest rate paths. On average, both the MPC and the BA markets see eye to eye concerning the future path of short term interest rates although the BA is usually not an unbiased forecast of the CDHI's committee views. Nevertheless, when the sample is broken down into pre and post conditional commitment samples, there is a striking divergence between market and expert views. Ever since the Bank of Canada provided forward guidance there is a complete absence of predictive power from the BA to MPC views about future interest rate paths. Figure 2, discussed earlier, suggests that we should not be surprised at such as result. Additional data going forward may reveal a narrowing of the differences between the two sources of future views about shortterm interest rates.

We now turn to asking whether there are observables that can be used to explain how the MPC revises its future interest rate path over time. The results are displayed in Table 3 . To determine the sensitivity of the results according to the type of voter on the MPC separate

\footnotetext{
${ }^{16}$ One obvious difference between the Bank of Canada and the Fed studied by Blinder (2004) is that the former follows a numerical inflation target while the latter central bank did not at the time. Differences in outlook (both inflation and real GDP growth, among other variables) could also be a factor resulting in biased forecasts. The Bank of Canada began publishing quarterly forecasts of inflation and real GDP growth in 2005. At this frequency, there were too few forecasts to consider including these in subsequent testing reported below.
} 
estimates are shown for the median, doves and hawks on the committee. The type of voter impacts the explanatory power of the regression with observables almost twice as capable of explaining changes in the MPC's future interest rate path for the median versus the dovish voters on the committee. Nevertheless, the regressions find that few forward looking variables are statistically significant. Whereas a rise in the VIX, namely a rise in uncertainty or volatility, results in a reduction in future interest rate recommendations, changes in forecasts of inflation are irrelevant. If such forecasts are believed to primarily drive how the Bank of Canada sets the policy rate there is little indication that forecasts serve as a coordination mechanism in setting the stance of monetary policy. In contrast, there is some evidence that Canadian (and euro area) economic growth forecasts influence the hawks and doves on the committee. In both cases better economic prospects serve to raise the future interest rate path. Notice, however, that hawks are more than twice a sensitive to better forecasts of economic growth than their more dovish counterparts on the committee. Of course, it needs to be stressed that the period under investigated is dominated by the events since the financial crisis erupted in the summer of 2007. Hence, it is perhaps not surprising that inflation forecasts took a back seat to real GDP growth forecasts in influencing the views of MPC committee members.

The previous results make it clear that there is disagreement about future interest rate paths within the MPC. Hence, we calculate the standard deviation of interest rate path proposals which serves as our indicator of path disagreement. We evaluate this measure for three distinct points along the future path, namely the extent of disagreement over the recommended policy rate in the upcoming Bank of Canada announcement, the meeting after that as well as the 6 month ahead horizon. We then regress levels of disagreement on a variety 
of institutional and economic determinants described above. The results are displayed in Table 4. Once again, paralleling somewhat the results of Table 3, it is difficult to find observable macroeconomic, financial, or institutional determinants of disagreement over the path of interest rates 6 months ahead. Nevertheless, there is considerable persistence in the level of disagreement at this horizon. Turning to the other MPC settings, the conditional commitment period clearly reduced disagreement within the MPC. Whether this reflects Bank of Canada credibility or a widely held form of agreement about the prospects for, say, future inflation and the need to commit to unchanged policy rates during this period is unclear. However, since the impact of this episode dissipates after the upcoming setting this represents a little bit of evidence that the conditionality was taken seriously by the median voter in the committee.

Regardless of the impact of the forward guidance of the Bank of Canada introduced in April 2009 disagreement vis-à-vis the Bank of Canada's previous policy rate setting raises MPC disagreement over future interest rates. Similarly, it is worth highlighting that recommended cuts in the policy rate by the MPC generate twice as much disagreement as do hikes in the recommended overnight rate. Clearly, views about the appropriate stance of future monetary policy inside the MPC, produce asymmetric views with a consequent statistically impact on path disagreement.

\section{Conclusions}

In the past decade or so, monetary policy decisions are typically obtained after a committee has deliberated and voted on a proposal. In Canada, while a Governing Council (GC) is the forum where such deliberations take place the Governor remains statutorily responsible for setting 
the stance of monetary policy. As a result, neither minutes nor votes of the GC are published. While a committee structure is ordinarily believed to deliver better decisions there are also risks associated with this form of decision-making, particularly around the manner in which information is transmitted and the impact this can have on voting.

In this paper, we examine the shadow Monetary Policy Council that is organized by the C.D. Howe non-partisan think tank. Given the structure of the committee, how decision-making takes place, as well as the voting arrangements of the committee, the MPC does not face the same information cascades and group polarization risks faced by actual decision-makers in central bank monetary policy councils. Members are individually accountable but, more importantly in an era that has come to be increasingly dominated by forward guidance and where central bank policy rates no longer represent a sufficient indicator of the stance of monetary policy, the CDHI's MPC also provides a forward interest rate path. The Bank of Canada does not publish such a path. This paper investigates the determinants of the MPC's recommendations and the relationship, if any, between the MPCs published views and market determined forward rates as well as actual future decisions taken by the Bank of Canada.

The empirical evidence presented in this paper reveals that there is considerable diversity of opinion about the recommended future path of interest rates inside the MPC. Virtually all MPC members recommended that the Bank of Canada implement a 'lift-off' of policy rates except during the height of the global financial crisis. It is only by the middle of 2013, when it became clear, based on the forward guidance of other major central banks (i.e., the U.S., the 
ECB, and the Bank of England), that MPC members delayed the timing of a 'lift-off' of the overnight rate in Canada.

Estimates also suggest that, beginning with the explicit forward guidance provided by the Bank of Canada between April 2009 and April 2010, market determined forward rates, as represented by the 3 months forward bankers' acceptance yields, diverge considerably from the recommendations implied by the MPC. Additionally, there is little evidence that the Bank and the MPC coordinate their future views about the interest rate path. Nevertheless, the fact that it is difficult to find observable institutional, macroeconomic or financial factors to explain the basis on which the median voter inside the MPC, as well as doves and hawks on the committee, change their views about future changes in policy rates implies that there remain challenges to understand the evolution of future interest rate paths over time. This remains the subject of future research. 


\section{References}

Bank of England (2013), "Forward Guidance", http://www.bankofengland.co.uk/monetarypolicy/Pages/forwardguidance.aspx.

Blinder, A. (2004), Quiet Revolution: Central Banking Goes Modern, New Haven (Conn.): Yale University Press.

Carney, M. (2013), “Monetary Policy after the Fall”, Eric J. Hanson Memorial Lecture, University of Alberta, http://www.bankofcanada.ca/2013/05/speeches/monetary-policy-after-thefall/.

Carney, M. (2013a), "Canada Works", Speech given to the Board Of Trade of Metropolitan Montreal, 21 May, http://www.bankofcanada.ca/2013/05/publications/speeches/canadaworks/.

Coeuré, B. (2013), "The Economic Consequences of Low Interest Rates", Public Lecture at the International Center for Monetary and Banking Studies, 9 October, http://www.ecb.europa.eu/press/key/date/2013/html/sp131009.en.html.

He, Z. (2010), "Evaluating the Effect of the Bank of Canada's Conditional Commitment Policy", Bank of Canada Discussion Paper 2010-11.

Karagedikli, Ö., and P. L. Siklos (2013) “A Bridge Too Far? RBNZ Communication, The Forward Interest Rate Track, and the Exchange Rate", in P.L. Siklos and J.E. Sturm (Eds.), Central Bank Transparency, Decision-Making, and Governance: The Issues, Challenges, and Case Studies (Cambridge, Mass.: MIT Press - 2013), pp.273-309.

Kool, C., and D. Thornton (2012), "How Effective is Central Bank Forward Guidance?”, working paper, Federal Reserve Bank of St. Louis 2012-063A, December.

Laidler, D.E.W. (1991), “How Shall We Govern the Governor? A Critique of the Governance of the Bank of Canada", The Canada Round 1 (Toronto: C.D. Howe Institute).

Maier, P. (2010), "How Central Banks Tae Decisions: An Analysis of Monetary Policy Meetings", in P. Siklos, M. Bohl, and M. Wohar (Eds.), Challenges in Central Banking: Cambridge University Press, 320-56. 
Manley, J., and M Dorin (1992), "The Mandate and Governance of the Bank of Canada: First Report of the Sub-Committee on the Bank of Canada", $8^{\text {th }}$ Report of the Standing Committee on Finance (Ottawa: Government of Canada).

Newey, W. and K. West (1987), "A Simple, Positive Semi-definite, Heteroskedasticity and Autocorrelation Consistent Covariance Matrix", Econometrica 55: 703-8.

Poole, W. (2006), "The Fed's Monetary Policy Rule", Review of the Federal Reserve Bank of St. Louis 88: 1-11.

Powell, J. (2009), The Bank of Canada of James Elliot Coyne (Montreal: McGill-Queens University Press).

Sibert, A. (2006), “Central Banking By Committee”, International Finance 9: 145-68.

Siklos, P. L. and A. Spence (2010), "Face-Off: Should the Bank of Canada Release its Projections of the Interest Rate Path", C.D. Howe Backgrounder No. 139.

Siklos, P. L., and M. Neuenkirch (2013), "How Monetary Policy is Made: Two Canadian Tales", unpublished working paper, September.

Taylor, J. (1993), "Discretion versus Policy Rules in Practice", Carnegie-Rochester Conference Series on Public Policy 39: 195-214.

Thornton, D., and D. Wheelock (2000), "A History of the Asymmetric Policy Directive", Review of the Federal Reserve Bank of St. Louis, 82 (September/October): 1-16.

Weale, M. (2013), "Forward Guidance and Its Effects", Speech given at the National Institute of Economic and Social Research, London, 11 December, http://www.bankofengland.co.uk/publications/Pages/speeches/2013/697.aspx.

White, H. (1980), “A Heteroskedasticity-consistent Covariance Matrix Estimator and a Direct Test for Heteroskedasticity", Econometrica 48: 817-38.

Williams, J.C. (2013), "Forward Guidance at the Federal Reserve", Published in Forward Guidance: Perspectives from Central Bankers, Scholars and Market Participants, Centre for Economic Policy Research (CEPR): London. 
Woodford, M. (2012), "Methods of Policy Accommodation at the Interest-Rate Lower Bound", Presented at "The Changing Policy Landscape" 2012 FRB Kansas City Economic Policy Symposium, Jackson Hole, WY. 


\section{Figures}

Figure 1: 6 Month Ahead MPC Proposal: Minimum, Median, and Maximum

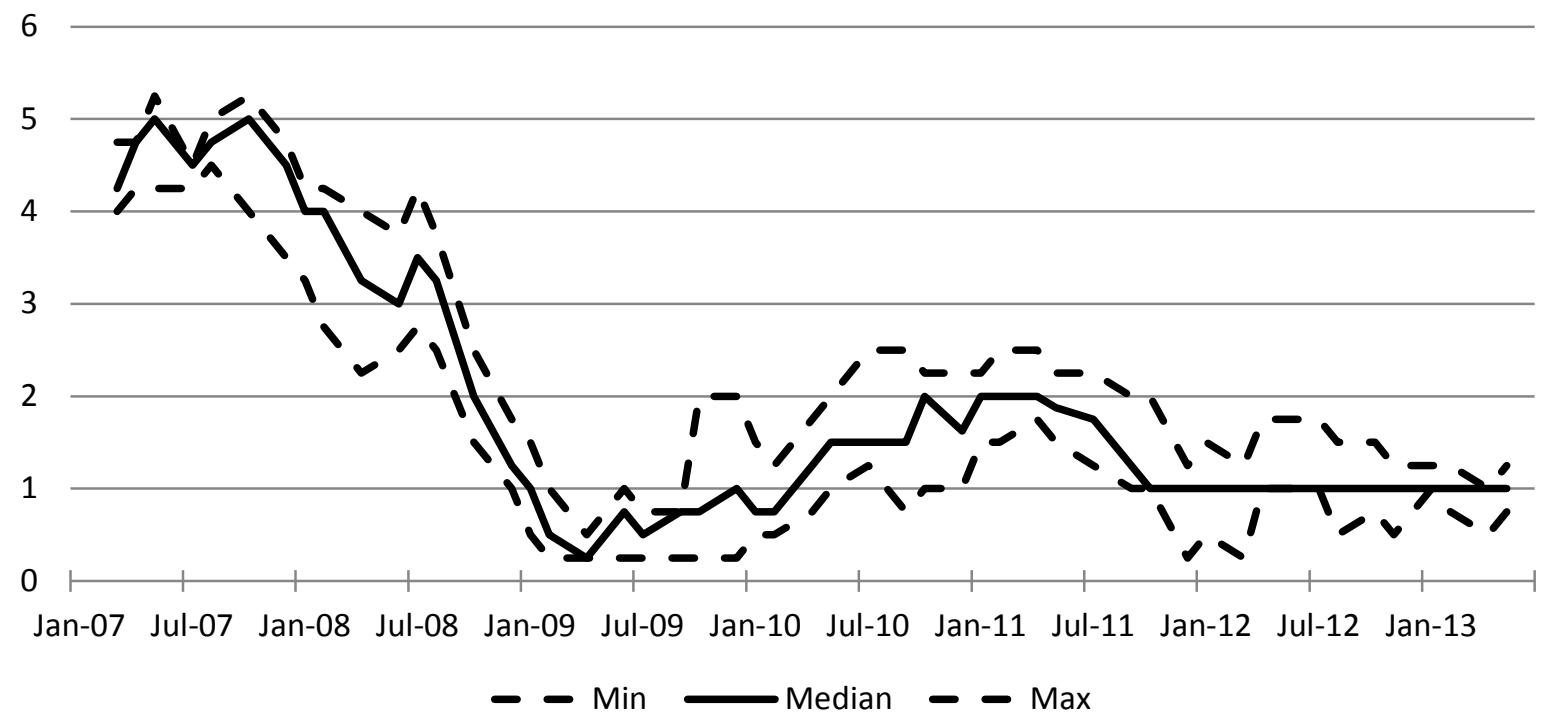

Figure 2: 6 Month Ahead MPC Median Proposal, BA 3 Months, and Actual BoC Policy Rate Setting in 6 Months

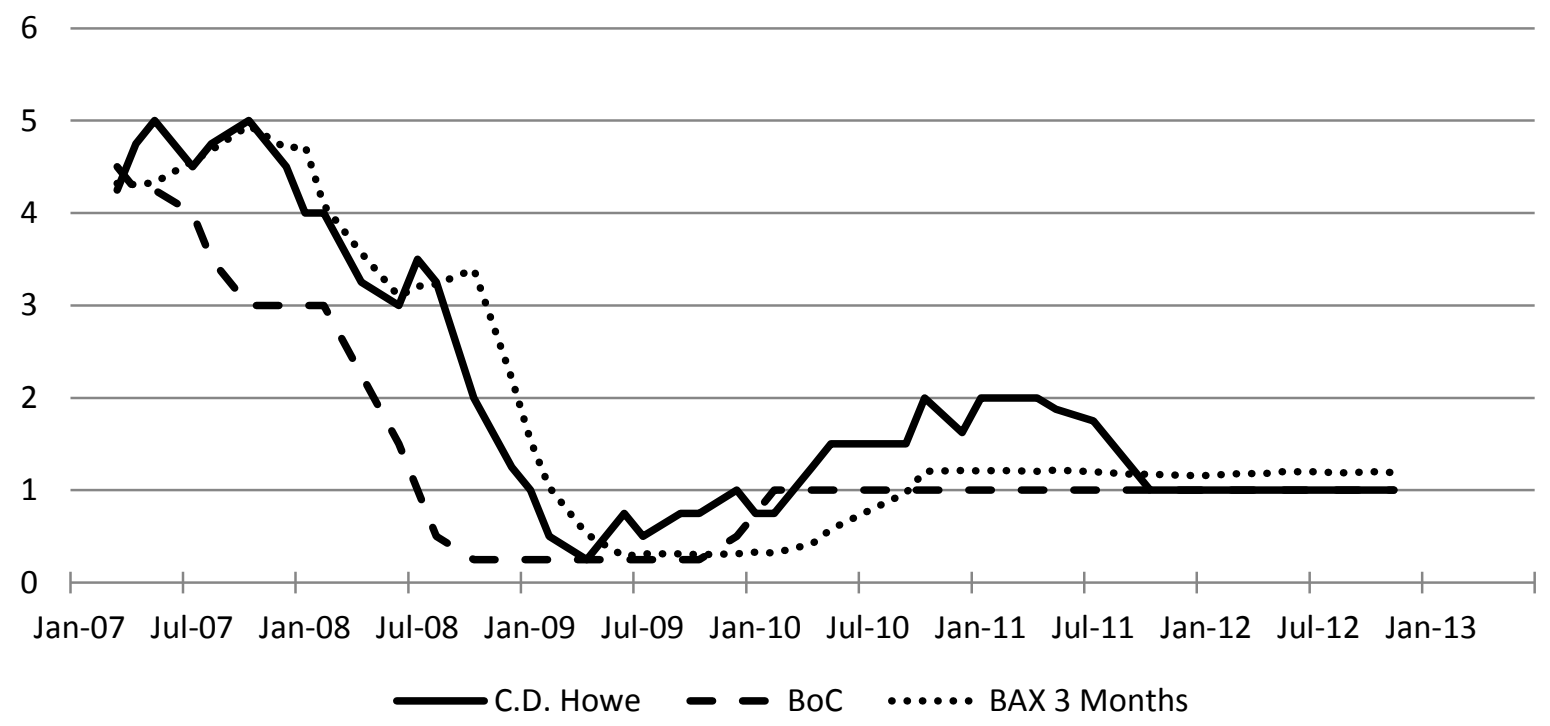


Figure 3: Difference between Upcoming MPC Proposal and Lagged 6 Months Ahead MPC Proposal versus Change in the Bank of Canada's Policy Rate during this Period

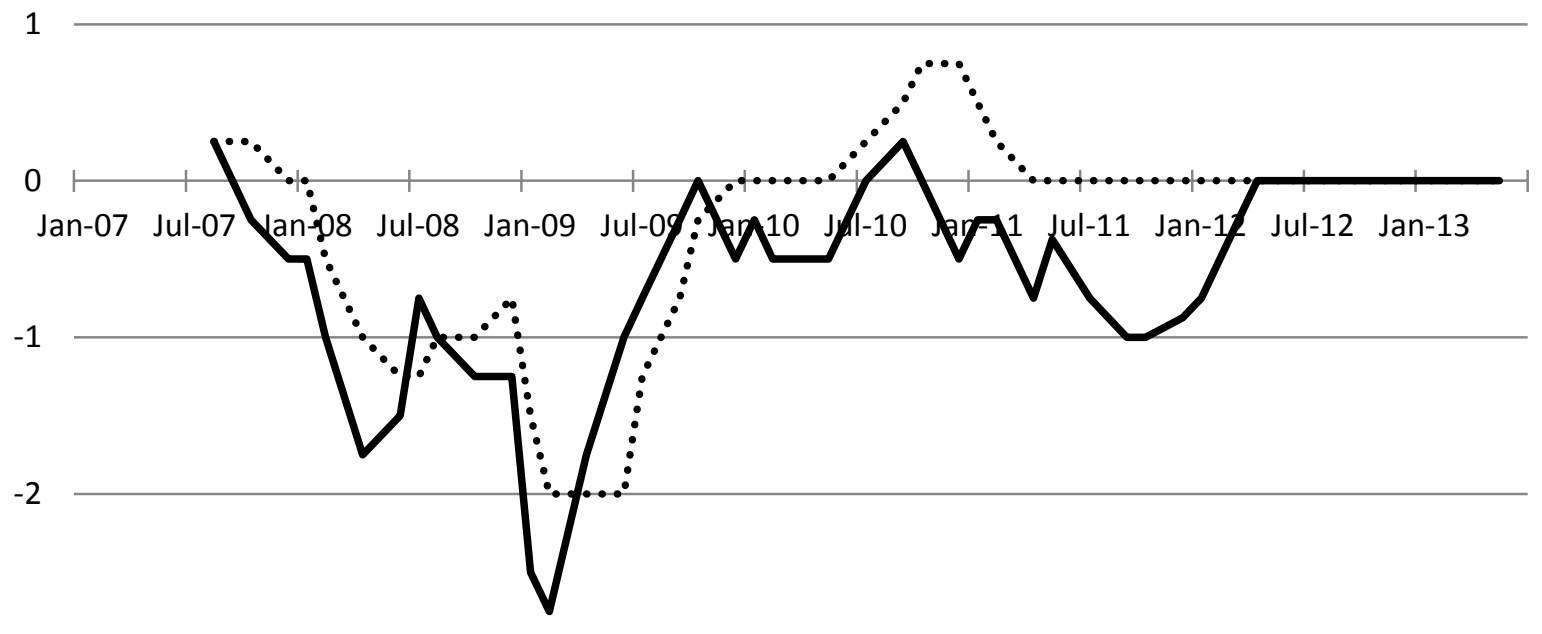
$-3$

$\longrightarrow$ Difference C.D. Howe $\quad$..... Difference BoC

Figure 4: Standard Deviation of Individual MPC Proposals for Three Different Horizons

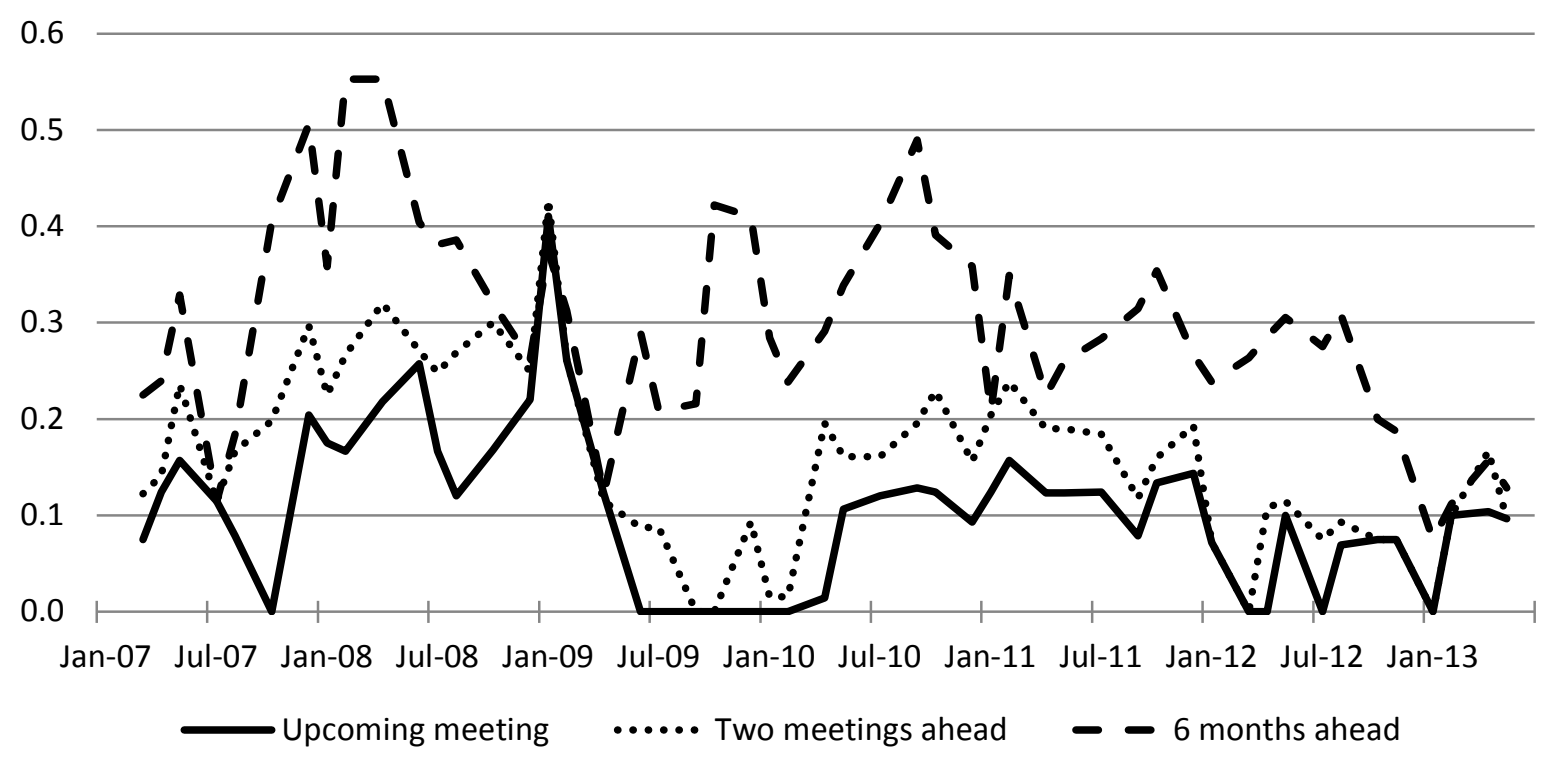




\section{Tables}

Table 1a: "Forecasting" the BoC's 6 Months Ahead Interest Rate with ...

\begin{tabular}{lcccc}
\hline & CD Howe Min. & CD Howe Med. & CD Howe Max. & 3M BA \\
\hline Constant & 0.14 & -0.10 & $-0.50^{* *}$ & 0.15 \\
Explanatory Variable & $0.81^{* * *}$ & $0.73^{* * *}$ & $0.75^{* * *}$ & $0.65^{* * *}$ \\
\hline Observations & 47 & 47 & 47 & 47 \\
R-Squared & 0.81 & 0.78 & 0.73 & 0.68 \\
S.E. of Regression & 0.53 & 0.57 & 0.63 & 0.68 \\
Unbiasedness & 4.29 & $22.07 * * *$ & $83.57 * * *$ & $9.77^{* * *}$ \\
\hline
\end{tabular}

Notes: The respective explanatory variable is indicated in the top line. OLS estimates with Newey/West standard errors are used. Last line shows test statistic for forecasts unbiasedness.

Table 1b: "Forecasting" the BoC's 6 Months Ahead Interest Rate: the pre-Conditional Commitment Period

\begin{tabular}{lcccc}
\hline & CD Howe Min. & CD Howe Med. & CD Howe Max. & \multicolumn{1}{c}{3 M BA } \\
\hline Constant & -0.54 & -0.75 & $-1.11^{*}$ & $-1.28^{*}$ \\
Explanatory Variable & $1.01^{* * *}$ & $0.89^{* * *}$ & $0.90^{* * *}$ & $0.99^{* * *}$ \\
\hline Observations & 18 & 18 & 18 & 18 \\
R-Squared & 0.82 & 0.77 & 0.70 & 0.67 \\
S.E. of Regression & 0.72 & 0.81 & 0.92 & 0.96 \\
Unbiasedness & $4.74 *$ & $16.50 * * *$ & $21.96 * * *$ & $15.37^{* * *}$ \\
\hline
\end{tabular}

Notes: The respective explanatory variable is indicated in the top line. OLS estimates with Newey/West standard errors are used. Last line shows test statistic for forecasts unbiasedness. 
Table 2a: "Forecasting" the 6 Months Ahead MPC Recommendation with 3 Months BAs

\begin{tabular}{lccc}
\hline & CD Howe Min. & CD Howe Med. & CD Howe Max. \\
\hline Constant & -0.01 & $0.33^{*}$ & $0.95^{* * *}$ \\
3M BA & $0.81^{* * *}$ & $0.89^{* * *}$ & $0.82^{* * *}$ \\
\hline Observations & 47 & 47 & 47 \\
R-Squared & 0.87 & 0.89 & 0.85 \\
S.E. of Regression & 0.48 & 0.48 & 0.54 \\
Unbiasedness & $12.12^{* * *}$ & 4.54 & $25.42^{* * *}$ \\
\hline
\end{tabular}

Notes: OLS estimates with Newey/West standard errors are used. Last line shows test statistic for forecasts unbiasedness. $* * * / * * *$ indicates significance at the $1 \% / 5 \% / 10 \%$ level.

Table 2b: "Forecasting" the 6 Months Ahead MPC Recommendation with 3 Months BAs: the pre-Conditional Commitment Period

\begin{tabular}{lrrr}
\hline & CD Howe Min. & CD Howe Med. & CD Howe Max. \\
\hline Constant & $-0.82^{* *}$ & $-0.68^{* *}$ & -0.06 \\
3M BA & $1.01^{* * *}$ & $1.14^{* * *}$ & $1.07 * * *$ \\
\hline Observations & 18 & 18 & 18 \\
R-Squared & 0.86 & 0.92 & 0.90 \\
S.E. of Regression & 0.56 & 0.47 & 0.49 \\
Unbiasedness & $25.93 * * *$ & $5.89 *$ & 3.08
\end{tabular}

Notes: OLS estimates. Newey/West standard errors are used in case of the minimum proposal. Last line shows test statistic for forecasts unbiasedness. ${ }^{* * *} / * * / *$ indicates significance at the $1 \% / 5 \% / 10 \%$ level.

Table 2c: "Forecasting" the 6 Months Ahead Proposal with 3 Months BAs: Results for the postConditional Commitment Period

\begin{tabular}{lccc}
\hline & CD Howe Min. & CD Howe Med. & CD Howe Max. \\
\hline Constant & $0.96^{* *}$ & $1.49^{* * *}$ & $2.59^{* * *}$ \\
3M BA & 0.00 & -0.10 & -0.58 \\
\hline Observations & 21 & 21 & 21 \\
R-Squared & 0.00 & 0.00 & 0.05 \\
S.E. of Regression & 0.42 & 0.43 & 0.44 \\
Unbiasedness & $7.86^{* *}$ & $81.61 * * *$ & $92.75 * * *$ \\
\hline
\end{tabular}

Notes: OLS estimates with Newey/West standard errors are used. Last line shows test statistic for forecasts unbiasedness. $* * * / * * / *$ indicates significance at the $1 \% / 5 \% / 10 \%$ level. 
Table 3: Explaining Changes in 6 Months Ahead Proposals: Allowing for International Influence

\begin{tabular}{lccc}
\hline & $\Delta$ (CD Howe Min.) & $\Delta$ (CD Howe Med.) & $\Delta$ (CD Howe Max.) \\
\hline Constant & -0.051 & -0.063 & -0.053 \\
$\Delta$ (Infl. Exp.) & -0.076 & 0.447 & -0.001 \\
$\Delta$ (GDP Exp.) & $0.211 *$ & 0.206 & $0.443 * * *$ \\
$\Delta$ (VIX) & -0.004 & $-0.023 * *$ & -0.007 \\
$\Delta$ (US Infl. Exp.) & -0.296 & -0.051 & -0.342 \\
$\Delta$ (US GDP Exp.) & -0.044 & 0.038 & -0.212 \\
$\Delta$ (EA Infl. Exp.) & 0.433 & -0.108 & 0.266 \\
$\Delta$ (EA GDP Exp.) & 0.383 & 0.112 & $0.498 * *$ \\
\hline Observations & 50 & 50 & 50 \\
R-Squared & 0.193 & 0.346 & 0.240 \\
S.E. of Regression & 0.335 & 0.308 & 0.401 \\
Standard Errors & White & White & $\mathrm{N} / \mathrm{W}$ \\
\hline Notes: OLS estimates of Equation (2) with standard errors as indicated in the last line. ${ }^{* * *} / * * *$ indicates $^{*}$ &
\end{tabular}

Table 4: Explaining the Standard Deviation of Individual Proposals

\begin{tabular}{lrrr}
\hline & Upcoming & Two Meet. Ahead & 6 Months Ahead \\
\hline Constant & $0.091^{* *}$ & $0.173 * * *$ & 0.118 \\
Lagged Dependent Variable & 0.157 & $0.246 *$ & $0.549 * * *$ \\
Share of Professionals & -0.037 & -0.091 & -0.010 \\
Share of In-Person Votes & -0.078 & -0.024 & 0.020 \\
Conditional Commitment & $-0.057^{* * *}$ & -0.014 & 0.095 \\
Lag Disagreement with BoC & $0.045^{* *}$ & 0.032 & 0.012 \\
Cut/Easing & $0.082^{* * *}$ & $0.099 * * *$ & -0.042 \\
Hike/Tightening & $0.041^{* *}$ & $0.039 * *$ & 0.020 \\
VIX & $0.001^{*}$ & 0.000 & 0.002 \\
Cond. Volatility of Inflation & -0.010 & -0.037 & -0.057 \\
\hline Observations & 50 & 50 & 50 \\
R-Squared & 0.714 & 0.632 & 0.410 \\
S.E. of Regression & 0.050 & 0.064 & 0.094 \\
Standard Errors & White & N/W & Normal \\
\hline Notes: OLS estimates of Equation (3) with standard errors as indicated in the last line. & $* * * * *$ indicates \\
significance at the 1\%/5\%/10\% level. & &
\end{tabular}




\section{Appendix}

Table A1: Dates of MPC and GC Meetings

\begin{tabular}{|c|c|c|c|c|}
\hline & MPC Meeting & MPC & GC Meeting & GC Decision \\
\hline 1 & August 28, 2003 & 2.75 & September 3, 2003 & 2.75 \\
\hline 2 & October 9, 2003 & 2.75 & October 15, 2003 & 2.75 \\
\hline 3 & November 27, 2003 & 2.75 & December 2, 2003 & 2.75 \\
\hline 4 & January 15, 2004 & 2.5 & January 20, 2004 & 2.5 \\
\hline 5 & February 26, 2004 & 2.25 & March 2, 2004 & 2.25 \\
\hline 6 & April 8, 2004 & 2.25 & April 13, 2004 & 2 \\
\hline 7 & June 3,2004 & 2.25 & June 8, 2004 & 2 \\
\hline 8 & July 15, 2004 & 2.25 & July 20, 2004 & 2 \\
\hline 9 & September 2, 2004 & 2.5 & September 8, 2004 & 2.25 \\
\hline 10 & October 14, 2004 & 2.75 & October 19, 2004 & 2.5 \\
\hline 11 & December 2, 2004 & 2.5 & December 7, 2004 & 2.5 \\
\hline 12 & January 20, 2005 & 2.5 & January 25, 2005 & 2.5 \\
\hline 13 & February 24, 2005 & 2.5 & March 1, 2005 & 2.5 \\
\hline 14 & April 7, 2005 & 2.5 & April 12, 2005 & 2.5 \\
\hline 15 & May 19, 2005 & 2.5 & May 25, 2005 & 2.5 \\
\hline 16 & July 7,2005 & 2.5 & July 12,2005 & 2.5 \\
\hline 17 & September 1, 2005 & 2.75 & September 7, 2005 & 2.75 \\
\hline 18 & October 13, 2005 & 3 & October 18, 2005 & 3 \\
\hline 19 & December 1, 2005 & 3.25 & December 6, 2005 & 3.25 \\
\hline 20 & January 19, 2006 & 3.5 & January 24, 2006 & 3.5 \\
\hline 21 & March 2, 2006 & 3.75 & March 7, 2006 & 3.75 \\
\hline 22 & April 20, 2006 & 4 & April 25, 2006 & 4 \\
\hline 23 & May 18, 2006 & 4.25 & May 24, 2006 & 4.25 \\
\hline 24 & July 6,2006 & 4.5 & July 11, 2006 & 4.25 \\
\hline 25 & August 31, 2006 & 4.25 & September 6, 2006 & 4.25 \\
\hline 26 & October 12, 2006 & 4.25 & October 17, 2006 & 4.25 \\
\hline 27 & November 30, 2006 & 4.25 & December 5, 2006 & 4.25 \\
\hline 28 & January 11, 2007 & 4.25 & January 16, 2007 & 4.25 \\
\hline $29^{1}$ & March 1, 2007 & 4.25 & March 6, 2007 & 4.25 \\
\hline 30 & April 19, 2007 & 4.25 & April 24, 2007 & 4.25 \\
\hline 31 & May 24, 2007 & 4.5 & May 29, 2007 & 4.25 \\
\hline 32 & July 5, 2007 & 4.5 & July 10, 2007 & 4.5 \\
\hline 33 & August 30, 2007 & 4.5 & September 5, 2007 & 4.5 \\
\hline 34 & October 11, 2007 & 4.5 & October 16, 2007 & 4.5 \\
\hline 35 & December 4, 2007 & 4.5 & December 4, 2007 & 4.25 \\
\hline 36 & January 17, 2008 & 4 & January 22, 2008 & 4 \\
\hline 37 & February 28, 2008 & 3.75 & March 4, 2008 & 3.5 \\
\hline 38 & April 17, 2008 & 3.25 & April 22, 2008 & 3 \\
\hline 39 & June 5, 2008 & 3 & June 10,2008 & 3 \\
\hline 40 & July 10, 2008 & 3.25 & July 15, 2008 & 3 \\
\hline
\end{tabular}




\begin{tabular}{|c|c|c|c|c|}
\hline 41 & August 28, 2008 & 3 & September 3, 2008 & 3 \\
\hline 42 & October 16, 2008 & 2 & October 21, 2008 & 2.25 \\
\hline 43 & December 4, 2008 & 1.75 & December 9, 2008 & 1.5 \\
\hline 44 & January 15, 2009 & 1 & January 20, 2009 & 1 \\
\hline 45 & February 26, 2009 & 0.5 & March 3, 2009 & 0.5 \\
\hline 46 & April 16, 2009 & 0.25 & April 21, 2009 & 0.25 \\
\hline 47 & June 2, 2009 & 0.25 & June 4, 2009 & 0.25 \\
\hline 48 & July 16, 2009 & 0.25 & July 21, 2009 & 0.25 \\
\hline 49 & September 8, 2009 & 0.25 & September 10, 2009 & 0.25 \\
\hline 50 & October 15, 2009 & 0.25 & October 20, 2009 & 0.25 \\
\hline 51 & December 3, 2009 & 0.25 & December 8, 2009 & 0.25 \\
\hline $52^{2}$ & January 14, 2010 & 0.25 & January 19, 2010 & 0.25 \\
\hline 53 & February 25, 2010 & 0.25 & March 2, 2010 & 0.25 \\
\hline 54 & April 15, 2010 & 0.25 & April 20, 2010 & 0.25 \\
\hline 55 & May 27, 2010 & 0.5 & June 1, 2010 & 0.5 \\
\hline 56 & July 15,2010 & 0.75 & July 20,2010 & 0.75 \\
\hline 57 & September 2, 2010 & 1 & September 8, 2010 & 1 \\
\hline 58 & October 14, 2010 & 1.25 & October 19, 2010 & 1 \\
\hline 59 & December 2, 2010 & 1 & December 7, 2010 & 1 \\
\hline 60 & January 18, 2011 & 1.25 & January 18, 2011 & 1 \\
\hline 61 & February 24, 2011 & 1.25 & March 1, 2011 & 1 \\
\hline 62 & April 7, 2011 & 1.25 & April 12, 2011 & 1 \\
\hline 63 & May 26, 2011 & 1.25 & May 31, 2011 & 1 \\
\hline 64 & July 14, 2011 & 1.25 & July 19, 2011 & 1 \\
\hline 65 & September 1, 2011 & 1 & September 7, 2011 & 1 \\
\hline 66 & October 20, 2011 & 1 & October 25, 2011 & 1 \\
\hline 67 & December 1, 2011 & 1 & December 6, 2011 & 1 \\
\hline 68 & January 12, 2012 & 1 & January 17, 2012 & 1 \\
\hline 69 & March 6, 2012 & 1 & March 8, 2012 & 1 \\
\hline 70 & April 12, 2012 & 1 & April 17, 2012 & 1 \\
\hline 71 & May 31, 2012 & 1 & June 5, 2012 & 1 \\
\hline 72 & July 12, 2012 & 1 & July 17, 2012 & 1 \\
\hline 73 & August 30, 2012 & 1 & September 5, 2012 & 1 \\
\hline 74 & October 18, 2012 & 1 & October 23, 2012 & 1 \\
\hline 75 & November29, 2012 & 1 & December 4, 2012 & 1 \\
\hline 76 & January 17, 2013 & 1 & January 23, 2013 & 1 \\
\hline 77 & February 28,2013 & 1 & March 6, 2013 & 1 \\
\hline 78 & April 11, 2013 & 1 & April 17, 2013 & 1 \\
\hline 79 & May 23, 2013 & 1 & May 29, 2013 & 1 \\
\hline
\end{tabular}

Notes: (1) 6 months ahead recommendation introduced; (2) 1 year ahead recommendation introduced. 2 policy rate settings ahead exist since the inception of the MPC. 
Table A2 Illustration of Forward Guidance provided by the CDHI's Monetary Policy Council:

November 28, 2013

\begin{tabular}{|c|c|c|c|c|}
\hline MPC Members & Dec. 4 & Jan. 22 & 6 months & 12 months \\
\hline$\frac{\text { Craig Alexander }}{\text { TD Bank Group }}$ & $1.00 \%$ & $1.00 \%$ & $1.00 \%$ & $1.00 \%$ \\
\hline $\begin{array}{l}\text { Steve Ambler } \\
\text { Université du Québec à } \\
\text { Montréal (UQAM) }\end{array}$ & $1.00 \%$ & $1.00 \%$ & $1.00 \%$ & $1.25 \%$ \\
\hline$\frac{\text { Paul Beaudry }}{\text { University of British Columbia }}$ & $1.00 \%$ & $1.00 \%$ & $1.00 \%$ & $1.00 \%$ \\
\hline $\begin{array}{l}\text { Edward A. Carmichael } \\
\text { Ted Carmichael Global Macro }\end{array}$ & $1.00 \%$ & $0.75 \%$ & $0.75 \%$ & $0.75 \%$ \\
\hline$\frac{\text { Stéfane Marion }}{\text { National Bank }}$ & $1.00 \%$ & $1.00 \%$ & $1.00 \%$ & $1.00 \%$ \\
\hline $\begin{array}{l}\text { Angelo Melino } \\
\text { University of Toronto }\end{array}$ & $1.00 \%$ & $1.00 \%$ & $1.00 \%$ & $1.00 \%$ \\
\hline $\begin{array}{l}\text { Doug Porter } \\
\text { BMO Capital Markets }\end{array}$ & $1.00 \%$ & $1.00 \%$ & $1.00 \%$ & $1.00 \%$ \\
\hline $\begin{array}{l}\text { Christopher Ragan } \\
\text { McGill University and David } \\
\text { Dodge Chair in Monetary Policy, } \\
\text { C.D. Howe Institute }\end{array}$ & $1.00 \%$ & $1.00 \%$ & $1.25 \%$ & $1.25 \%$ \\
\hline$\frac{\text { Nicholas Rowe }}{\text { Carleton University }}$ & $0.75 \%$ & $0.75 \%$ & $1.00 \%$ & $1.00 \%$ \\
\hline$\frac{\text { Pierre Siklos }}{\text { Wilfrid Laurier University }}$ & $1.00 \%$ & $1.00 \%$ & $1.00 \%$ & $1.00 \%$ \\
\hline Median Vote & $1.00 \%$ & $1.00 \%$ & $1.00 \%$ & $1.00 \%$ \\
\hline
\end{tabular}

The views and opinions expressed by the participants are their own and do not necessarily reflect the views of the organizations with which they are affiliated, or those of the C.D. Howe Institute. 